\title{
Case study on complex sporadic E layers observed by GPS radio occultations
}

\author{
X. Yue ${ }^{1}$, W. S. Schreiner ${ }^{1}$, Z. Zeng ${ }^{1}$, Y.-H. Kuo ${ }^{1}$, and X. Xue ${ }^{2}$ \\ ${ }^{1}$ COSMIC Program Office, University Corporation for Atmospheric Research, Boulder, CO, USA \\ ${ }^{2}$ CAS Key Laboratory of Geospace Environment, Department of Geophysics \& Planetary Sciences, \\ University of Science \& Technology of China, Hefei, Anhui, China
}

Correspondence to: X. Yue (xinanyue@ucar.edu)

Received: 3 May 2014 - Published in Atmos. Meas. Tech. Discuss.: 10 September 2014

Revised: 3 December 2014 - Accepted: 8 December 2014 - Published: 12 January 2015

\begin{abstract}
The occurrence of sporadic $\mathrm{E}\left(\mathrm{E}_{\mathrm{s}}\right)$ layers has been a hot scientific topic for a long time. The GNSS (global navigation satellite system)-based radio occultation (RO) has proven to be a powerful technique for detecting the global $\mathrm{E}_{\mathrm{S}}$ layers. In this paper, we focus on some cases of complex $\mathrm{E}_{\mathrm{S}}$ layers based on the RO data from multiple missions processed in UCAR/CDAAC (University Corporation for Atmospheric Research (UCAR) the Constellation Observing System for Meteorology, Ionosphere, and Climate (COSMIC) Data Analysis and Archive Center (CDAAC)). We first show some examples of multiple $\mathrm{E}_{\mathrm{s}}$ layers occurred in one RO event. Based on the evaluations between colocated simultaneous $\mathrm{RO}$ events and between $\mathrm{RO}$ and lidar observations, it could be concluded that some of these do manifest the multiple $E_{\mathrm{S}}$ layer structures. We then show a case of the occurrence of $\mathrm{E}_{\mathrm{s}}$ in a broad region during a certain time interval. The result is then validated by independent ionosondes observations. It is possible to explain these complex $\mathrm{E}_{\mathrm{s}}$ structures using the popular wind shear theory. We could map the global $E_{S}$ occurrence routinely in the near future, given that more RO data will be available. Further statistical studies will enhance our understanding of the $\mathrm{E}_{\mathrm{S}}$ mechanism. The understanding of $E_{\mathrm{S}}$ should benefit both $\mathrm{E}_{\mathrm{S}}$-based long-distance communication and accurate neutral $\mathrm{RO}$ retrievals.
\end{abstract}

\section{Introduction}

The ionospheric E region is $\sim 90-120 \mathrm{~km}$ above the Earth's surface. Its electrons mainly originate from soft X-ray and far ultraviolet (UV) solar radiation ionization of the neutral atmosphere. The regular E region strictly follows the photochemistry equilibrium and therefore could be represented well by a function of the solar zenith angle (Yue et al., 2006). The ionospheric $\mathrm{E}$ region has a relatively higher electrical conductivity and therefore plays a crucial role in the ionosphere electron dynamics. The understanding of the E region could contribute to the studies related to electrojets of highlatitude and equatorial regions, ionospheric instabilities, and ionosphere-thermosphere-magnetosphere couplings. In addition, it is a key area for long-distance radio communication. Under certain circumstances, a thin layer of enhanced ionization appears in the $\mathrm{E}$ region, which is called the sporadic $\mathrm{E}$ layer $\left(E_{\mathrm{s}}\right)$. It can be denser than either the $\mathrm{E}$ layer peak or even the $\mathrm{F}$ layer peak. $\mathrm{E}_{\mathrm{s}}$ has been investigated extensively both theoretically and experimentally in the past century. It is generally accepted that $E_{S}$ is composed of metallic ions of meteoric origin converged vertically mainly by wind shear, especially in the middle latitude region (Axford, 1963). The wind shear theory has been confirmed by many independent observations and simulations (Haldoupis, 2011; Whitehead, 1989). The occurrence of $E_{S}$ is controlled by multiple factors, including tidal wind, the Earth's geomagnetic field, and meteoric deposition of metallic material in the background thermosphere. These factors result in variations of $E_{\mathrm{s}}$ occurrence with respect to local time, altitude, latitude, longitude, and season (Haldoupis, 2011). Furthermore, in the high-latitude region, the occurrence of $E_{S}$ is more significantly influenced by the local electric field rather than the wind shear due to the geomagnetic field difference (Wakabayashi and Ono, 2005). Please note that the term $E_{s}$ is now widely used to represent the inhomogeneity of the ionospheric E layer (e.g., layers, 


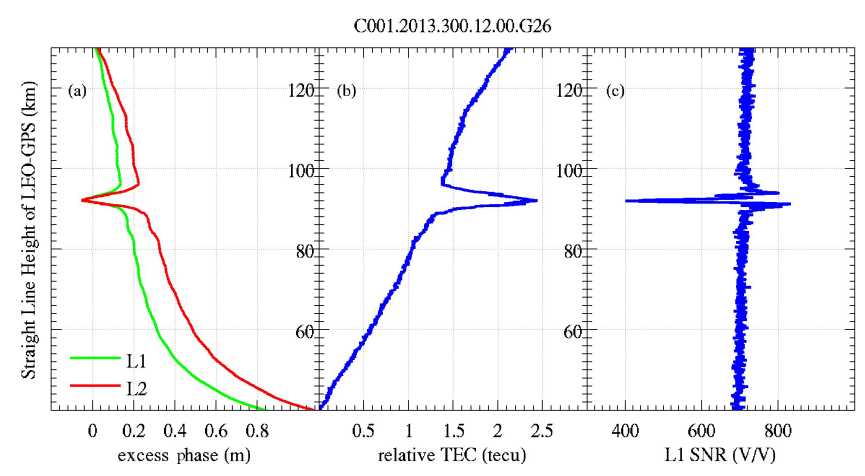

Figure 1. Straight line height variations of excess phase (a), relative slant TEC (b), and L1 SNR (c) of one selected radio occultation event observed by COSMIC FM1 on day 300 of 2013, when there was a sporadic E layer occurrence over the occultation region.

cloud, irregularity) rather than only the echo trace from the ionogram when it was discovered. To learn more about basic $\mathrm{E}_{\mathrm{S}}$ theory and research progress, the reader can refer to these review papers and the references therein: Haldoupis (2011) and Whitehead (1989).

Traditionally, $\mathrm{E}_{\mathrm{S}}$ is mainly observed by ground-based radars, including ionosonde and incoherent/coherent scatter radars (ISR, CSR), and occasional in situ probes carried by rockets. Recently, the GNSS (global navigation satellite system)-based radio occultation (RO) technique has shown great capability in detecting the global $\mathrm{E}_{\mathrm{S}}$ occurrence by using high-resolution signal-to-noise ratio (SNR) data (Arras et al., 2008; Chu et al., 2014; Hocke et al., 2001; Wu et al., 2005; Yeh et al., 2012; Zeng and Sokolovskiy, 2010). GNSS RO technique has proven to be a powerful tool in monitoring climate, weather, and space weather (Anthes, 2011; Foelsche et al., 2011; Liu et al., 2010; Schreiner et al., 2007; Zhang et al., 2011; Yue et al., 2012). After the pioneer GPS/MET (Global Positioning System/Meteorology) mission, many low-Earth-orbit (LEO) satellites were launched with a RO payload, including CHAMP (Challenging Minisatellite Payload), GRACE (Gravity Recovery And Climate Experiment), SAC-C/D (Scientific Application SatelliteC/D), COSMIC (Constellation Observing System for Meteorology, Ionosphere, and Climate), C/NOFS (Communications/Navigation Outage Forecasting System), Metop-A/B (Meteorological Operational Satellite Program of Europe - A/B), and TerraSAR-X (X-band Terra SAR)/TanDEM-X (TerraSAR-X add-on for Digital Elevation Measurements). These observations have accumulated a big database with which to study the $E_{\mathrm{s}}$. As an example, Fig. 1 shows the altitude variations of the excess phase, relative slant total electron content (TEC) along the LEO-GPS ray, and the SNR during a typical $E_{s}$ event. Due to the occurrence of the $E_{s}$, both the phase and SNR show simultaneous fluctuations. The SNR has an obvious U shape, as reported by Zeng and Sokolovskiy (2010). The obvious increase in slant TEC around $\sim 92 \mathrm{~km}$ implies the ionization enhancement in the $\mathrm{E}_{\mathrm{S}}$ layer. Based on all available GPS/MET RO data, Hocke et al. (2001) did a statistical analysis on the global $\mathrm{E}_{\mathrm{s}}$ occurrence and compared the results with the ionosonde observations. Wu et al. (2005) did a more robust statistical analysis on the global $\mathrm{E}_{\mathrm{s}}$ using CHAMP RO data. The detailed seasonal, latitude, local time, altitude, and hemisphere variations were studied. By combining almost all the available RO data, Arras et al. (2008) showed a finer structure of $E_{\mathrm{S}}$ occurrence. Specifically, they provided direct proof of the control exerted by the Earth's geomagnetic field on $\mathrm{E}_{\mathrm{s}}$ for the first time, and this supported the wind shear theory strongly (Haldoupis, 2011). These statistics are further confirmed by Chu et al. (2014) and Yeh et al. (2012), based on a large amount of COSMIC data. Through both simulation and real-data analysis, Zeng and Sokolovskiy (2010) revealed that the $\mathrm{E}_{\mathrm{s}}$ cloud aligned with the wave propagation direction could cause defocusing of the GPS RO signal, accompanied by scintillation above and below the defocusing region due to the interference of direct and refracted radio waves. These effects result in specific U-shape structures in the amplitude of the GPS RO signals. This $U$ shape will reduce and even disappear with the increase of the tilt angle of the $E_{S}$ cloud with respect to the wave direction. Furthermore, RO amplitude data are also used to detect the high-altitude ionospheric irregularity through either back propagation algorithms or analysis of the amplitude variation pattern (Sokolovskiy et al., 2002; Pavelyev et al., 2012; Wickert et al., 2004).

However, some investigations have shown that the $E_{s}$ could sometimes be much more complicated than a single layer. Smith and Miller (1980) reported the double-peaks $E_{\mathrm{s}}$ and even a rectangular $\mathrm{E}_{\mathrm{s}}$ layer observed by rockets. They concluded that the complex profiles of sporadic E layers can be interpreted as an effect of unstable wind shears. Based on high-resolution ISR observations over Arecibo, Mathews et al. (2001) reported some complex $E_{\mathrm{s}}$ layers, which might be due to the modulation of polarized electric fields linked with the F region. They reproduced the observed results through 3-D numerical simulations. In addition, some investigations pointed out that the drivers responsible for the plasma instability (e.g., the Kelvin-Helmholtz instability (KHI)) could deform the $\mathrm{E}_{\mathrm{S}}$ layer into a complex structure (Bernhardt, 2002; Cosgrove and Tsunoda, 2003). They could lift up part of the $E_{\mathrm{S}}$ layer to overlap with the original layer. Based on the SEEK-2 rocket campaign observations, Wakabayashi and Ono (2005) analyzed the double-peak $\mathrm{E}_{\mathrm{S}}$ layer phenomena in detail. They found that the lower peak is usually more stable than the upper peak. By using simultaneous neutral wind and electric field observations, they showed that the neutral wind shear is mainly responsible for the generation of the lower layer, while the direct current (DC) electric field makes a significant contribution to the formation of the upper layer. However, the complex $\mathrm{E}_{\mathrm{S}}$ layer can only be observed with the higher vertical resolution technique, such as ISR/CSR and rocket (Chu and Wang, 1997; Hysell et al., 2012). However, 
there are no corresponding routinely and globally distributed observations publicly available, especially not from the ISR and rockets; this is not cost effective. According to Haldoupis (2011), the sporadic E layer is actually not spatially or temporally sporadic either. However, it has been difficult in the past to identify the $\mathrm{E}_{\mathrm{S}}$ layer simultaneously in a broad region due to the available sparse ground-based observations. The GNSS RO measurements can provide the quasi-vertical profile of the ionosphere globally and routinely. It offers us a potential way to study these complex $\mathrm{E}_{\mathrm{s}}$ layer phenomena .

In this paper, we will conduct some case studies on multiple $\mathrm{E}_{\mathrm{s}}$ events observed by COSMIC as well as other missions' atmospheric RO data, which are observed by the occultation antennas of each LEO satellite with a $\sim 50 \mathrm{~Hz}$ resolution. Specifically, two kinds of cases will be investigated. One is multiple $\mathrm{E}_{\mathrm{s}}$ occurring in a local region observed by one occultation. The other is multiple $\mathrm{E}_{\mathrm{s}}$ occurring over a broad region observed by many simultaneous RO events. Multiple $\mathrm{E}_{\mathrm{s}}$ phenomena have been touched on by some previous studies (Hocke et al., 2001; Yeh et al., 2012). Yeh et al. (2012) even conducted a statistical analysis of the multiple $\mathrm{E}_{\mathrm{S}}$ layer distribution using $\sim 3$ years of COSMIC RO data. Their results show that the multiple $\mathrm{E}_{\mathrm{S}}$ layers have a distribution that, with respect to geographic location and time, is very similar to the previous studies by Wu et al. (2005) and Arras et al. (2008). Our study has the following significance in comparison with previous studies. (1) According to Haldoupis (2011), wind shear below $\sim 115 \mathrm{~km}$ is dominated by zonal wind, while meridional wind dominates above this altitude due to the altitude variation of the collision frequency between ions and neutrals. This will therefore result in different duration and tidal structures of the $E_{S}$ layers at different altitudes. Studies on multiple $\mathrm{E}_{\mathrm{s}}$ layers in the same location will be helpful in $\mathrm{E}_{\mathrm{S}}$ mechanism understanding. (2) As indicated by Zeng and Sokolovskiy (2010), a nonlocal tilted $\mathrm{E}_{\mathrm{S}}$ layer could cause the less significant fluctuation of SNR in the lower altitude of the local RO event. It increases the difficulty of identifying the multiple $\mathrm{E}_{\mathrm{s}}$ layers by using only one RO event. In this study, we will show how to identify this phenomenon by multiple colocated RO events. (3) We will show how simultaneously observed RO events in a large broad region enable us to demonstrate that the $\mathrm{E}_{\mathrm{S}}$ is not sporadic spatially. (4) The bending angle and therefore the refractivity/temperature in the lower atmosphere $\mathrm{RO}$ retrievals are influenced significantly by small-scale ionospheric irregularities, especially the $\mathrm{E}_{\mathrm{s}}$ layer (Mannucci et al., 2011). A better understanding of $\mathrm{E}_{\mathrm{S}}$ in $\mathrm{RO}$ signals will benefit the improvement of neutral atmosphere retrievals and therefore numerical weather prediction (NWP) and climate change study.

The remainder of the paper is organized as follows. Section 2 shows the examples of multiple-peak $E_{\mathrm{s}}$ layers in the same location. The example of $\mathrm{E}_{\mathrm{s}}$ occurring in a broad region simultaneously observed by multiple RO events is given in Sect. 3. We then discuss and conclude in Sects. 4 and 5, respectively.

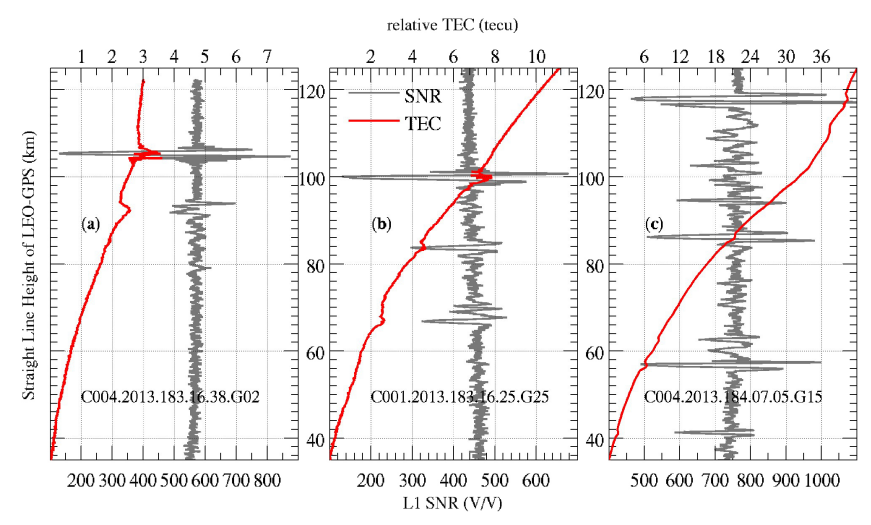

Figure 2. Selected examples of two (a), three (b), and multiple (c; in this case, seven) peaks in the L1 SNR and relative slant TEC versus straight line height observed by COSMIC satellites.

\section{Case study 1: multiple-peak $E_{s}$ layer in the same location}

The identification of $E_{\mathrm{s}}$ occurrence is different from paper to paper (Arras et al., 2008; Chu et al., 2014; Dou et al., 2010; Hocke et al., 2001; Wu et al., 2005; Yeh et al., 2012; Zeng and Sokolovskiy, 2010). Hocke et al. (2001) and Dou et al. (2010) derived $E_{s}$ occurrence from the fluctuations of RO inverted electron density profiles. Wu et al. (2005) and Arras et al. (2008) calculated the standard deviation of filtered and normalized SNR and identified $E_{\mathrm{S}}$ occurrence through either the maximum standard deviation or a threshold. Chu et al. (2014) applied a stricter criterion on both the amplitude and phase fluctuations of L1 and L2 signals to avoid potential influences from the instrument and measurement noise. In this study, the $50 \mathrm{~Hz}$ amplitude and phase observations made by the COSMIC occultation antennas and archived at the University Corporation for Atmospheric Research (UCAR) COSMIC Data Analysis and Archive Center (CDAAC) level1b atmPhs files will be used. The amplitude scintillation index S4 and relative slant TEC are calculated based on the $50 \mathrm{~Hz}$ SNR and excess phase, respectively. Only the cases that have a maximum $\mathrm{S} 4$ index calculated from $50 \mathrm{~Hz}$ SNR larger than 0.3 are considered. $\mathrm{E}_{\mathrm{s}}$ occurrence will then be identified manually from case to case. Only the cases that show visible fluctuations of L1/2 SNR and phases and obvious enhancement of slant TEC around the E region will be considered.

\subsection{Multiple-peak $\mathrm{E}_{\mathrm{s}}$ examples}

As stated, the $\mathrm{E}_{\mathrm{S}}$ layer can cause the defocusing and scintillation of the SNR of RO signals. So the $E_{S}$ occurrence can be identified from the fluctuation of the SNR. In the meantime, the enhanced ionization in the $E_{S}$ layer also results in an additional phase delay of the radio signal and therefore the enhancement of the slant TEC along the GNSS ray. When we looked at the RO data case by case, we can find many cases 

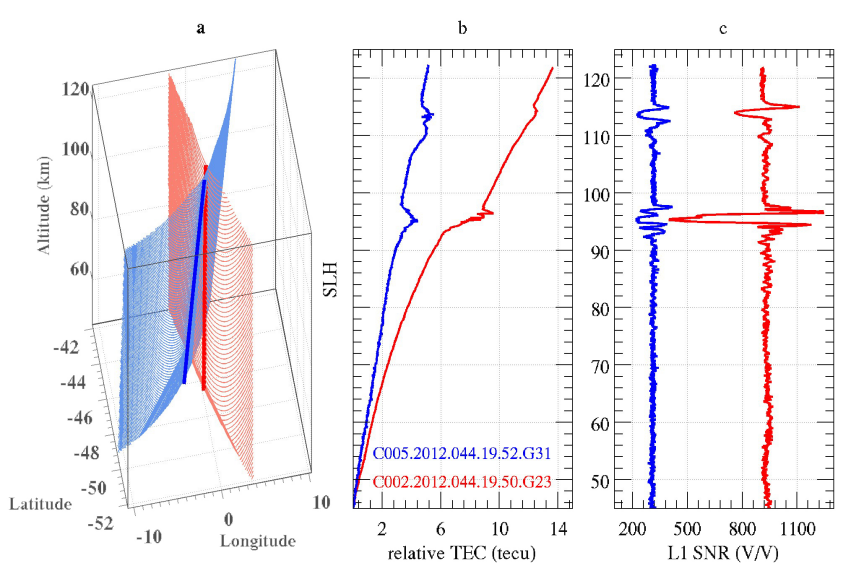

Figure 3. Two colocated RO events, which present two peaks in either relative TEC or L1 SNR versus straight line height, observed by different COSMIC LEO satellites at the same time on day 44 of 2012: (a) occultation plane and corresponding tangent points; (b) relative slant TEC versus straight line height (SLH); (c) L1 SNR versus straight line height. Blue and red represent two different RO events.

that have more then one peak in SNR or slant TEC along the tangent height. We give three typical such examples in Fig. 2. The case in Fig. 2a was observed by COSMIC satellite FM4 on day 183 of 2013. Both SNR fluctuation and slant TEC show major and minor peaks around $\sim 105$ and $93 \mathrm{~km}$. In Fig. $2 \mathrm{~b}$ case, the SNR/TEC shows one larger peak around $\sim 100 \mathrm{~km}$ and two smaller peaks around 84 and $67 \mathrm{~km}$, respectively. Figure $2 \mathrm{c}$ shows an extreme case with up to seven visible peaks in both SNR fluctuation and slant TEC. Please note that the much larger range of TEC amplitude here makes its enhancements less visible, although the TEC peaks are actually significant in this case. Due to the special observational geometry of RO, either the SNR or the slant TEC actually reflects the integral effect along the whole GNSS ray. When we assign these values to the tangent points of the GNSS ray, the effect of the $\mathrm{E}_{\mathrm{s}}$ layer in the higher altitude could map down to the lower tangent point altitude, which might result in pseudo multiple peaks along the tangent point altitude, as shown in Fig. 2 (Zeng and Sokolovskiy, 2010). However, the $\mathrm{E}_{\mathrm{s}}$ layer mostly extends horizontally. For a specific GNSS ray, the effect of $E_{\mathrm{s}}$ far from the tangent points will be much smaller than that of $E_{S}$ in the tangent points area due to the tilt angle between $\mathrm{E}_{\mathrm{S}}$ layer and GNSS ray. In the following, we will show two kinds of validation studies on multiple $\mathrm{E}_{\mathrm{s}}$ peaks in the same RO event.

\subsection{Evaluation by colocated simultaneous RO events}

In UCAR/CDAAC, we process most RO data available to the scientific community (Schreiner et al., 2011). This comes from missions including COSMIC, CHAMP, GRACE, SACC, TerraSAR-X, C/NOFS, and MetopA/B. These combined missions can generate 3000-4000 RO events daily in terms
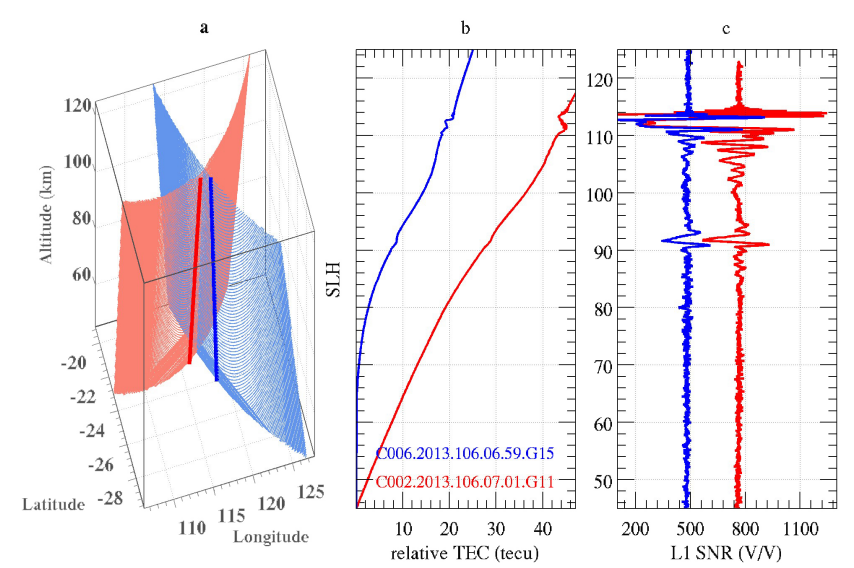

Figure 4. The same as Fig. 3 but for another case on day 106 of 2013.

of atmospheric excess phase (atmPhs). This number varies with time due to either satellite launching or degradation. One potential way to evaluate multiple $\mathrm{E}_{\mathrm{s}}$ layers is looking at the colocated RO events. If two colocated RO events with totally different azimuth angles show similar multiple $E_{\mathrm{s}}$ structures at the same time, we can conclude that these structures are realistic structures. We searched the colocated RO events among all CDAAC data during 2012-2013. The Metop data are excluded because Metop usually begins to sample occultation around at an altitude of $\sim 80 \mathrm{~km}$. The colocation criteria is that the difference in latitude, longitude, and universal time at an altitude of $100 \mathrm{~km}$ of the tangent point between two occultations is less than 1 degree, 2 degree, and $15 \mathrm{~min}$, respectively. This criterion is far smaller than the typical spatial and temporal scales of $\mathrm{E}_{\mathrm{s}}$. In addition, the azimuth angle difference between two occultations at an altitude of $100 \mathrm{~km}$ should be larger than 60 degrees to ensure that the areas away from the tangent points of two occultations have no overlap. Those short occultations having no integral coverage of $90-120 \mathrm{~km}$ will be discarded too. The excess phase, SNR, and relative slant TEC of these colocated occultations were printed out to be checked further manually. Generally, we can find $\sim 6-10$ colocated RO pairs per day on average. Unfortunately, some of them either have no $E_{\mathrm{s}}$ occurrence or only one peak $E_{\mathrm{s}}$, a matter which is beyond the scope of this study. Finally, we found $\sim 100$ cases manually in which both colocated occultations show visible double peaks in both SNR and slant TEC at the same tangent point altitude. Since two occultations sample a totally different area and intersect with each other in the tangent point area, there is a high possibility that these double-peak $\mathrm{E}_{\mathrm{S}}$ layers are the realistic double $E_{\mathrm{s}}$ layers occurring around the tangent points area. As examples, we show two such cases in Figs. 3 and 4. In Fig. 3, two occultations made by COSMIC FM5-GPS31 and FM2-GPS23 within 2 min around the southern middle latitude on day 44 of 2012 at local sunset are displayed. Indicated by SNR and TEC variations, two $\mathrm{E}_{\mathrm{s}}$ lay- 


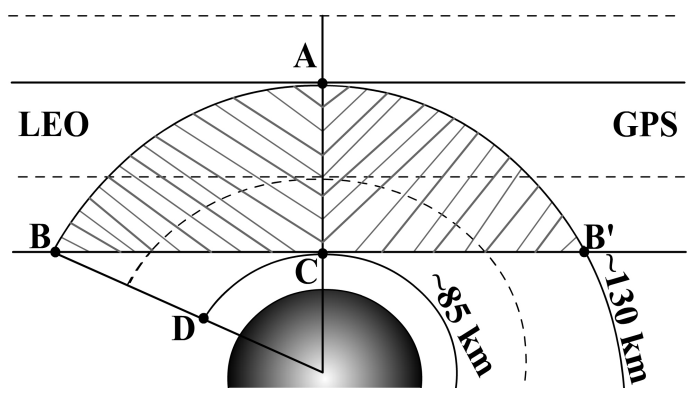

Figure 5. The $\mathrm{E}_{\mathrm{S}}$ occurrence area (EOA) is defined by the shaded area in the picture.

ers around 114 and $95 \mathrm{~km}$ occurred simultaneously in two occultations. In another case shown in Fig. 4, two simultaneous occultations made by FM6-GPS15 and FM2-GPS11 around the southern middle-latitude area during the afternoon are shown. One major peak at around $113 \mathrm{~km}$ and another minor peak at around $92 \mathrm{~km}$ can be identified in both occultations. The SNRs around the two peaks have an obvious U shape, which indicates that the tilt angle between $\mathrm{E}_{\mathrm{S}}$ direction and GPS ray is insignificant (Zeng and Sokolovkiy, 2010).

\subsection{Independent evaluation by lidar observations}

According to Gardner et al. (1993), sporadic metal (Fe and $\mathrm{Na}$ ) layers could be observed simultaneously with the sporadic $\mathrm{E}$ layer due to the neutralization of metal ions $\left(\mathrm{Fe}^{+}\right.$ and $\mathrm{Na}^{+}$) in the associated $\mathrm{E}_{\mathrm{s}}$ layer. Dou et al. (2010) have compared the $\mathrm{E}_{\mathrm{s}}$ derived from COSMIC electron density profiles with the meteors from a meteor radar and the sodium atom layers from a lidar statistically. Well-correlated seasonal variations were detected among three parameters. It implies a link between $\mathrm{E}_{\mathrm{S}}$ and metal layers. Another potential way to evaluate these multiple-peak $E_{\mathrm{s}}$ layers is by comparing them with lidar results. In this study, the lidar observations made in Beijing $\left(40.2^{\circ} \mathrm{N}, 116.2^{\circ} \mathrm{E}\right)$, Hefei $\left(31.8^{\circ} \mathrm{N}\right.$, $\left.117.3^{\circ} \mathrm{E}\right)$, Wuhan $\left(30.5^{\circ} \mathrm{N}, 114.4^{\circ} \mathrm{E}\right)$, and Haikou $\left(19.5^{\circ} \mathrm{N}\right.$, $109.1^{\circ} \mathrm{E}$ ) over China, accessed through the Chinese Meridian Project during 2012, are used (Wang, 2011). Detailed information about these lidar stations can be found in Dou et al. (2013). Based on these lidar observations, Dou et al. (2013) carried out statistical investigations into the occurrence of sporadic sodium layers (SSLs) and the thermosphere enhanced sodium layers (TeSLs) in China during 2011-2012. The TeSLs is defined as the secondary sodium layer in the lower thermosphere, separated from the main SSLs (Dou et al., 2013). We are not going to look at all the lidar observations in this study. Instead, we tried to search the COSMIC RO events nearby the lidar stations for the TeSLs cases listed in Table A2 of Dou et al. (2013). These TeSLs were all observed during local nighttime and their duration ranges from $\sim 1 \mathrm{~h}$ up to $\sim 6 \mathrm{~h}$. The colocation criteria are that the difference in latitude and longitude between lidar and RO tangent points at the altitude of $100 \mathrm{~km}$ is less than $2.5^{\circ}$ and $4.5^{\circ}$, respectively, and the occurrence time of RO is within the TeSLs occurrence. Of all 28 cases, we finally found a perfect case for 29 July 2012 (DOY: 211) over Haikou lidar station. Before showing the results of this case, we would like to define a concept called the $\mathrm{E}_{\mathrm{S}}$ occurrence area (EOA) for convenience. As shown in Fig. 5, the peaks of either SNR or TEC in tangent point $C$ could only originate from the $E_{s}$ layers located above that altitude along the BB' GNSS ray. Usually, the $E_{\mathrm{s}}$ layer occurs in the altitude range of $85-130 \mathrm{~km}$ (Haldoupis, 2011). We do not consider the intermediate layer because most RO missions were designed to untertake highresolution sampling around $130 \mathrm{~km}$ (Arras et al., 2009; Li et al., 2013). So the $E_{\mathrm{S}}$ layers in the plots could only come from the area between 85 and $130 \mathrm{~km}$ that the GNSS rays pass through. This area is defined as EOA, indicated by the shaded area in Fig. 5. In the TeSLs case over Haikou lidar station from 29 July 2012, the TeSLs begins to separate from the main SSL at around $\sim 15: 00$ (UT), becomes distinguishable at 15:32, peaks at around 16:00 at an altitude of $113 \mathrm{~km}$, and ends at 18:19. During the whole TeSLs occurrence interval, there exist significant SSLs with peaks around $\sim 93 \mathrm{~km}$. There are a total of four COSMIC colocated ROs observed at 15:20, 15:30, 15:50, and 16:03. The first two ROs are made by COSMIC FM2 and occurred in the initial phase of TeSLs, while the latter two are by FM1 around the peak of TeSLs. Figure 6 shows the geolocation of the Haikou lidar station and the EOA of the four colocated RO events. The EOA of the four ROs have few overlaps, which implies that the $E_{s}$ observed by the RO events are independent. The SNR/TEC of RO events and the Na density of Haikou lidar corresponding to the RO occurrence time are given in Fig. 7. As indicated by the altitude variations of the SNR/TEC, all four $\mathrm{RO}$ events show obvious complex $\mathrm{E}_{\mathrm{S}}$ occurrences. In case 1, the occultation is in southwest-northeast direction and move over the Haikou lidar station. The SNR/TEC show simultaneous fluctuations in the altitude range of $85-110 \mathrm{~km}$. While in case 2, the RO event is $\sim 500 \mathrm{~km}$ west of Haikou and the SNR/TEC fluctuates at almost all the altitudes. In both cases, the SNR oscillations are not constant and show some minor peaks occasionally. This excludes the potential effects from the F region ionospheric scintillations (Straus et al., 2003). During the occurrence of cases 1 and 2, the TeSLs separates from the main SSL. Since the TeSLs is mainly formed from the neutralization of metal ions, the ionosphere might experience complicated dynamic and chemistry evolutions during the initial phase of TeSLs. RO measurements confirmed that the ionization is complicated and no distinct layered structures are formed at that time, which is consistent with the Na density observations. In cases 3 and 4, the TeSLs are already distinguishable. Both RO events show two peaks at $\sim 100$ and $108 \mathrm{~km}$, respectively, in terms of either SNR or slant TEC. In case 3, the higher-altitude peak is smaller than the lower peak, while the situation is reversed in case 4 . This might be caused by the different geometry of occultation, 


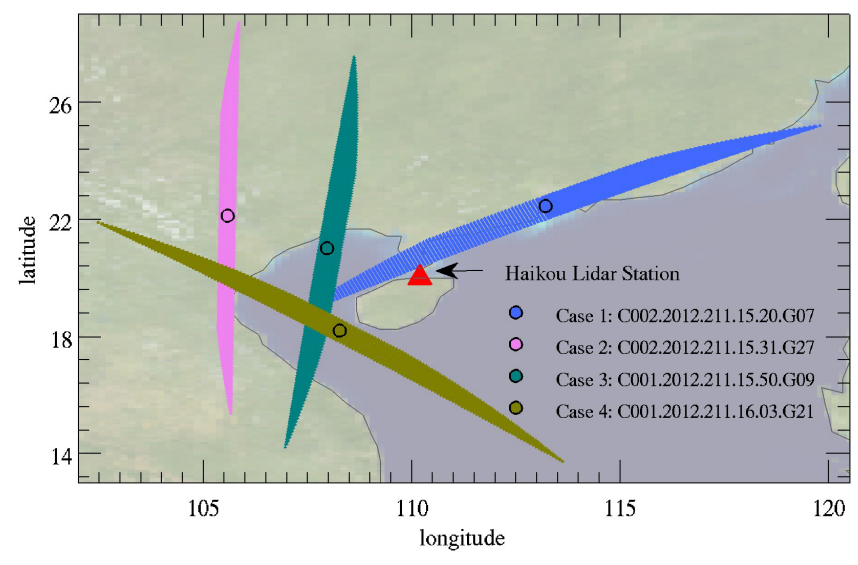

Figure 6. The red triangle represents the location of Haikou lidar station over China. The shaded areas show the $\mathrm{E}_{\mathrm{S}}$ occurrence area (EOA) for the four colocated RO events observed by COSMIC, represented by four colors. The points at which the straight line height is $100 \mathrm{~km}$ are marked by the black circles.

which results in the difference of the tilt angle between $E_{S}$ and GNSS ray. Please note that the peak altitude and amplitude are not necessarily consistent between RO and lidar observations due to the different dynamic processes involved. The Na density used here mainly serves to demonstrate the potential existence of multiple $\mathrm{E}_{\mathrm{s}}$ layers in the ionosphere, which is confirmed by the RO measurements.

\section{Case study 2: multiple simultaneous $\mathbf{E}_{\mathrm{s}}$ layers in a broad region}

$\mathrm{E}_{\mathrm{S}}$ was mainly observed by the ionosondes in the early stage. $\mathrm{E}_{\mathrm{S}}$ can only be identified by ionosonde when it is larger than a certain value because most ionosonde transmitters have a low limitation on the transmitted wave frequency $(\sim 1-$ $1.5 \mathrm{MHz})$. It makes the appearance of $\mathrm{E}_{\mathrm{S}}$ "sporadic" regarding space and time (Haldoupis, 2011). However, the wind shear theory suggests that $\mathrm{E}_{\mathrm{s}}$ is closely linked to the atmospheric dynamics. Inherently, this implies that $\mathrm{E}_{\mathrm{s}}$ possesses a variable but regular character that reflects both the complexity and repeatability of the atmospheric wind and wave dynamics in the mesosphere-lower-thermosphere (MLT) region. The high-resolution and sensitivity observations made by ISR in Arecibo have confirmed that $\mathrm{E}_{\mathrm{S}}$ is present at all times in some cases, which exhibit a non-sporadic behavior (Mathews, 1998). Mathews (1998) even proposed an alternative term "tidal ion layers (TIL)" because "sporadic" is an instrumental limitation rather than a prominent physical property (Haldoupis, 2011). The ISR observations already prove the non-sporadic property of $\mathrm{E}_{\mathrm{s}}$ with respect to time. However, due to the lack of global $\mathrm{E}_{\mathrm{s}}$ observations, there is still no direct evidence to prove that $\mathrm{E}_{\mathrm{S}}$ was also spatially nonsporadic in the past. The global distribution feature of RO technique enables us to find direct evidence for the first time.
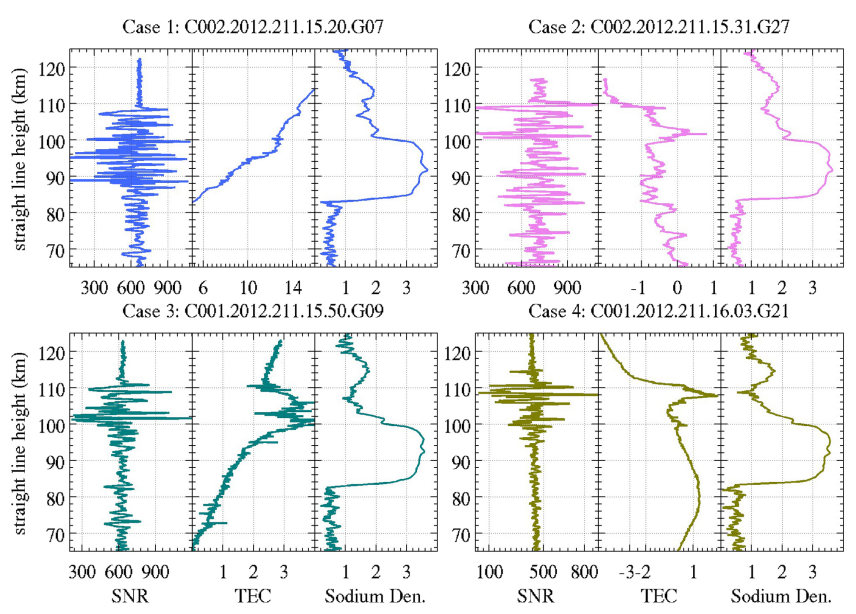

Figure 7. Altitude variations of L1 SNR and relative slant TEC of $\mathrm{RO}$ events and $\mathrm{Na}$ density of lidar observations corresponding to the four cases shown in Fig. 6. The unit of $\mathrm{Na}$ density is $\mathrm{cm}^{-3}$ and is represented logarithmically in the plots.

Although we can observe 3000-4000 RO events daily and globally by the combined multiple RO missions, it is still impossible to get enough occultations for a certain time and space range. Fortunately, right after the launch, the six COSMIC satellites were clustered together in one orbit and the distances between LEOs increased gradually (Schreiner et al., 2007). It enables tracking multiple RO events in a broad region simultaneously in the initial stage of LEO orbit separation. We looked through all the COSMIC RO data as well as occultations available from other missions during 2006. Finally, we found many cases in which multiple LEOs sample a certain region at a certain time. Some of these cases show that the $\mathrm{E}_{\mathrm{s}}$ can occur in a broad region simultaneously, which supports the idea that $\mathrm{E}_{\mathrm{s}}$ is non-sporadic spatially too. These cases are mainly found in the middle latitude of Eurasian continent and the Pacific Ocean. This is logical because the relatively higher horizontal component of the geomagnetic field over this region makes the wind shear more efficient (Haldoupis, 2011). To evaluate these results, the raw ionograms accessed from the Digital Ionogram DataBase (DIDB) operated by the Lowell Global Ionospheric Radio Observatory (GIRO) Data Center (LGDC) through the SAO Explorer software are used to make an independent comparison (Galkin et al., 1999; Reinisch and Galkin, 2011). For 2006, a total of about 35-40 ionosonde stations shared their data in DIDB. Generally, Europe and northern America have relatively more and denser ionosonde distributions. We checked the ionograms over these regions during the occurrence of simultaneous $\mathrm{E}_{\mathrm{S}}$ over a broad region indicated by RO. For most cases, we can find the visible $E_{s}$ occurrence in the corresponding ionograms. Figures 8-11 show such an example over Europe.

On day 294 of 2006 (21 October), five satellites of COSMIC, excluding FM5, which was already raised to a higher 


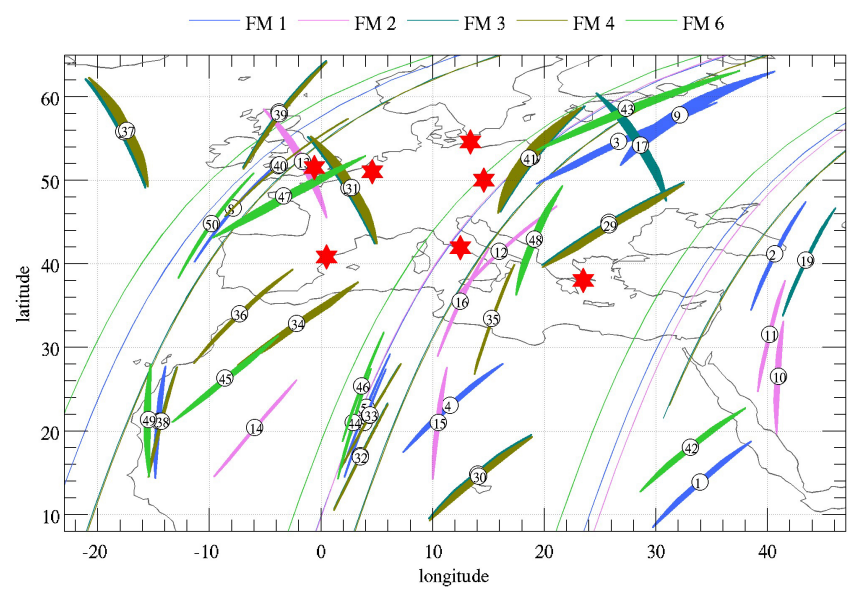

Figure 8. Longitude and latitude distributions of the $E_{S}$ Occurrence Area (EOA) of $50 \mathrm{RO}$ events observed by COSMIC during 2006.294, 11:00-15:00 UT over and surrounding Europe region. The circle on each EOA is the corresponding tangent point at an altitude of $100 \mathrm{~km}$ with the case serial number embedded. The light lines are the orbits of COSMIC LEO satellites during this time interval. Different colors represent different COSMIC FM satellites. The red stars show the location of seven ionosondes used.

orbit, have adjacent orbits. FM3 and FM4 even have almost the same orbit within a distance of $200 \mathrm{~km}$. A total of 62 RO events were observed over $10-60^{\circ}$ latitude and $-20-45^{\circ}$ longitude area during 11:00-15:00 UT interval. Through our manual checking, we found that 50 of them show obvious $\mathrm{E}_{\mathrm{s}}$-related oscillations in SNR. Figure 8 shows the LEOs' orbits and these $50 \mathrm{RO}$ events. The EOA is again shown here for each occultation to demonstrate the independence of the observed $\mathrm{E}_{\mathrm{S}}$ between different ROs. Each occultation is labeled by an index number (1-50). The corresponding altitude variations of SNR are shown in Fig. 9. Note that the SNR is normalized to the range of $0-1$ for convenience. As indicated in the figure, all the ROs selected here show obvious oscillations related to $E_{s}$. Most of the SNRs have a visible U shape, which illustrates that the $E_{\mathrm{s}}$ is significant. At this specific region and time interval, the DIDB has seven ionosondes that have observations available. The geolocation, ionosonde system type, and the operation organization are given in Table 1. The red stars in Fig. 8 represent the geographic distribution of the ionosondes. The hourly ionograms of seven ionosondes during 11:00-15:00 UT are plotted in Fig. 10, with an emphasis on the wave traces below $150 \mathrm{~km}$, indicated by black dots. We can see clearly the wave traces due to the $E_{\mathrm{s}}$ in most ionograms except in 11:00 and 12:00 UT of Athens. Please note the different noise level between the ionograms by different types of ionosondes. In Fig. 11, we plotted the automatically scaled $E_{s}$ critical frequency (foEs) and the E layer critical frequency (foE) of seven ionosondes and the averaged International Reference Ionosphere (IRI) modeled foE versus local time (Bilitza and Reinisch, 2008). The high oc- currence rate of $E_{S}$ can be identified. Although these seven ionosondes are distributed in a relatively narrow area, they still strongly support the simultaneous occurrence of $E_{S}$ over a broad region.

\section{Discussion}

\subsection{Multiple $\mathbf{E}_{\mathrm{s}}$ layers in one profile}

We have summarized some complex $\mathrm{E}_{\mathrm{s}}$ layers observed by rockets and ISRs from previous publications (Smith and Miller, 1980; Mathews et al., 2001; Bernhardt, 2002; Cosgrove and Tsunoda, 2003; Wakabayashi and Ono, 2005). In Sect. 2, we reported some examples of RO events that show multiple peaks in the tangent altitude variations of either SNR or relative slant TEC; these manifest the potentially complex multiple layered structures of $E_{S}$ in the occultation area. In comparison with ISR and rocket measurement, which could manifest either a small or large scale of $E_{S}$ horizontally, the GNSS-RO-observed $\mathrm{E}_{\mathrm{s}}$ layer should have a relatively larger horizontal scale due to the lower horizontal resolution of RO observation (Schreiner et al., 2007; Zeng and Sokolovskiy, 2010). Then we showed some double-peak $E_{s}$ layers observed by simultaneously colocated RO events with different azimuth angles to prove that these double-peak $E_{\mathrm{s}}$ layers are probably not caused by the localization problem and could be realistic. Furthermore, we also gave an example of a comparison between the complex $\mathrm{E}_{\mathrm{s}}$ layers made by four RO events and the colocated lidar-observed double sporadic Na layers (TeSLs). With the development of TeSLs over time, RO measurements accordingly show complex $\mathrm{E}_{\mathrm{s}}$. Actually, Xue et al. (2013) also reported an example showing that the lidar observes TeSLs associated with simultaneous double peaks of SNR made by colocated RO events from TerraSAR-X. According to wind shear theory, at lower (upper) altitudes, the zonal (meridional) wind will dominate the shear due to the altitude variations of the ion-neutral collision frequency regarding the ion gyrofrequency ratio. In comparison with the low altitude, the $\mathrm{E}_{\mathrm{S}}$ layers in the upper altitude are more variable and short-lived since ion convergence is much faster there (Haldoupis, 2011). Similarly, an existing $\mathrm{E}_{\mathrm{s}}$ layer could be broadened and dissipated by an opposite wind shear. The layers can deform faster (slower) at the altitudes where they form faster (slower). This is the reason why $\mathrm{E}_{\mathrm{S}}$ layers remain fairly stable for many hours at lower heights, while their lifetime is much shorter at high altitude. The $\mathrm{E}_{\mathrm{S}}$ is controlled by the tidal wind and therefore also shows tidal structures in its formation and descent. Main tidal components can be diurnal, semidiurnal, and even terdiurnal and quarterdiurnal (Arras et al., 2009; Chu et al., 2014; Fytterer et al., 2013; Wu et al., 2005). All these factors make the complex $\mathrm{E}_{\mathrm{S}}$ layer structures understandable. However, due to the limited amount of data available from ISR and rockets, the investigations into this issue were mainly 


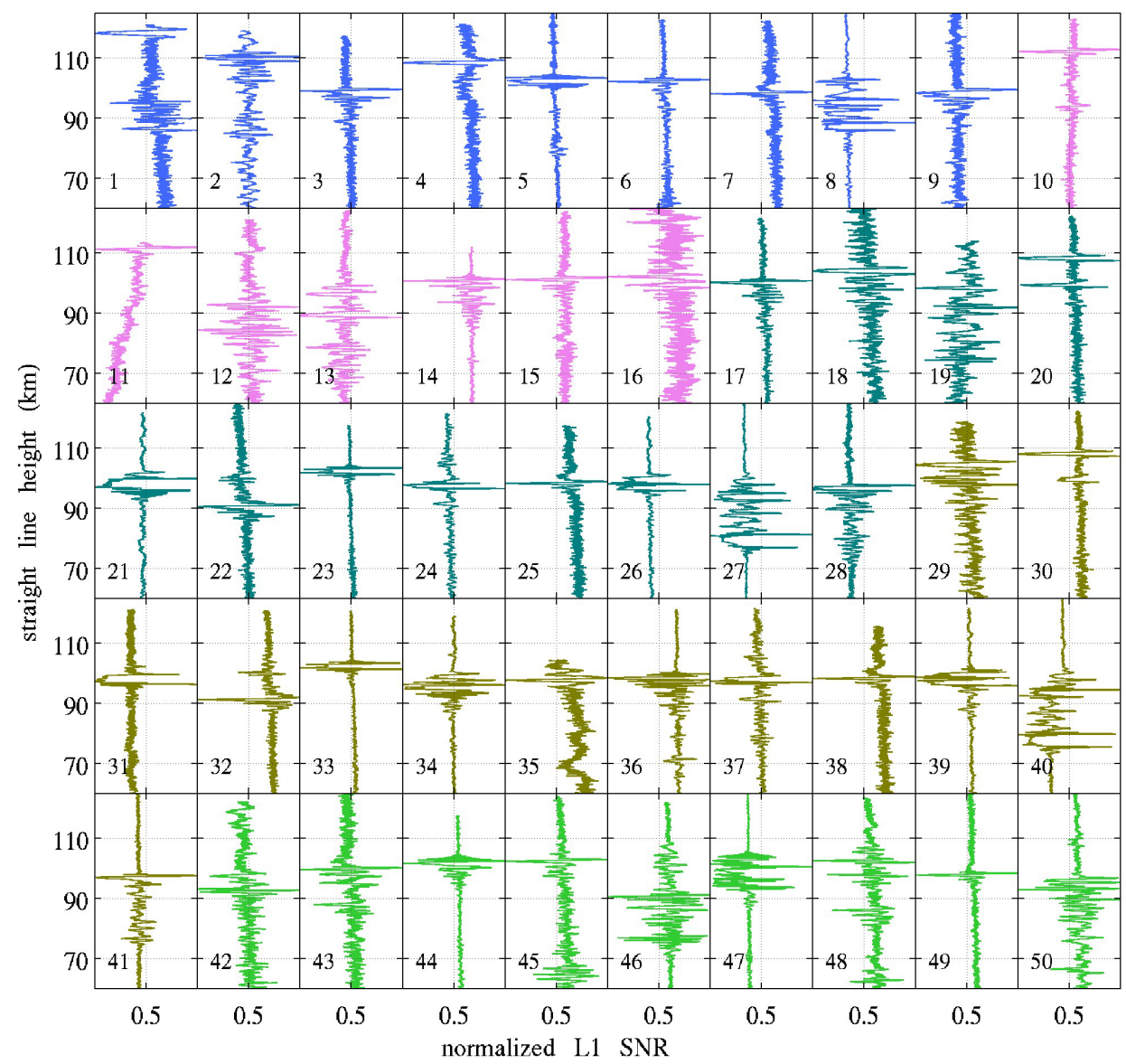

Figure 9. Straight line height variations of the normalized L1 SNR for the 50 COSMIC RO events shown in Fig. 8. Different colors represent different LEO satellites.

Table 1. Latitude, longitude, ionosonde system type, and operation organization/country of the seven ionosondes used in the study. DGS-256: Digisonde-256; DPS-1: Single-Receiver Digisonde Portable Sounder; DPS-4: Four-Receiver Digisonde Portable Sounder.

\begin{tabular}{lrrll}
\hline Station & Latitude & Longitude & Ionosonde & Organization/country \\
\hline Athens & $38.0^{\circ} \mathrm{N}$ & $23.5^{\circ} \mathrm{E}$ & DPS-4 & National Observatory of Athens, Greece \\
Dourbes & $50.1^{\circ} \mathrm{N}$ & $4.6^{\circ} \mathrm{E}$ & DGS-256 & Royal Meteorological Institute, Belgium \\
Roquetes & $40.8^{\circ} \mathrm{N}$ & $0.3^{\circ} \mathrm{E}$ & DGS-256 & Observatori de I'Ebre, Spain \\
Juliusruh & $54.6^{\circ} \mathrm{N}$ & $13.4^{\circ} \mathrm{E}$ & DPS-1 & Institute of Atmospheric Research, University of Rostock, Germany \\
Pruhonice & $50.0^{\circ} \mathrm{N}$ & $14.6^{\circ} \mathrm{E}$ & DPS-4 & Institute of Atmospheric Physics, Czech Republic \\
Chilton & $51.5^{\circ} \mathrm{N}$ & $0.6^{\circ} \mathrm{W}$ & DPS-1 & Rutherford Appleton Laboratory, United Kingdom \\
Rome & $41.9^{\circ} \mathrm{N}$ & $12.5^{\circ} \mathrm{E}$ & DPS-4 & L'Instituto Nazionale di Geofisica, Italy \\
\hline
\end{tabular}

made through either theoretical analysis or case studies. The huge amount of accumulated RO events enables us to study this phenomenon statistically, which will be done in a further study. This kind of investigation will definitely enhance our understanding of the $\mathrm{E}_{\mathrm{s}}$ mechanism.

\subsection{Simultaneous $\mathrm{E}_{\mathrm{s}}$ occurrence in a broad region}

We have found many cases that show simultaneous $\mathrm{E}_{\mathrm{s}}$ occurrence over a broad region made by clustered COSMIC satel- lites in the early stage. One of these cases is displayed in the paper and evaluated by the independent ionosonde observations. Regarding this comparison, we should be aware of two key points. (1) In the RO SNR profile, we can see that some cases show $\mathrm{E}_{\mathrm{s}}$ occurrence below even $80 \mathrm{~km}$. However, due to the localization problem of RO geometry, as stated above, these $E_{\mathrm{S}}$ could either happen at the altitude of the tangent point or at a higher altitude beyond the tangent point due to the mapping effect along the GNSS ray. If the $\mathrm{E}_{\mathrm{s}}$ occurs below $80 \mathrm{~km}$, it could not be the result of the wind shear theory 


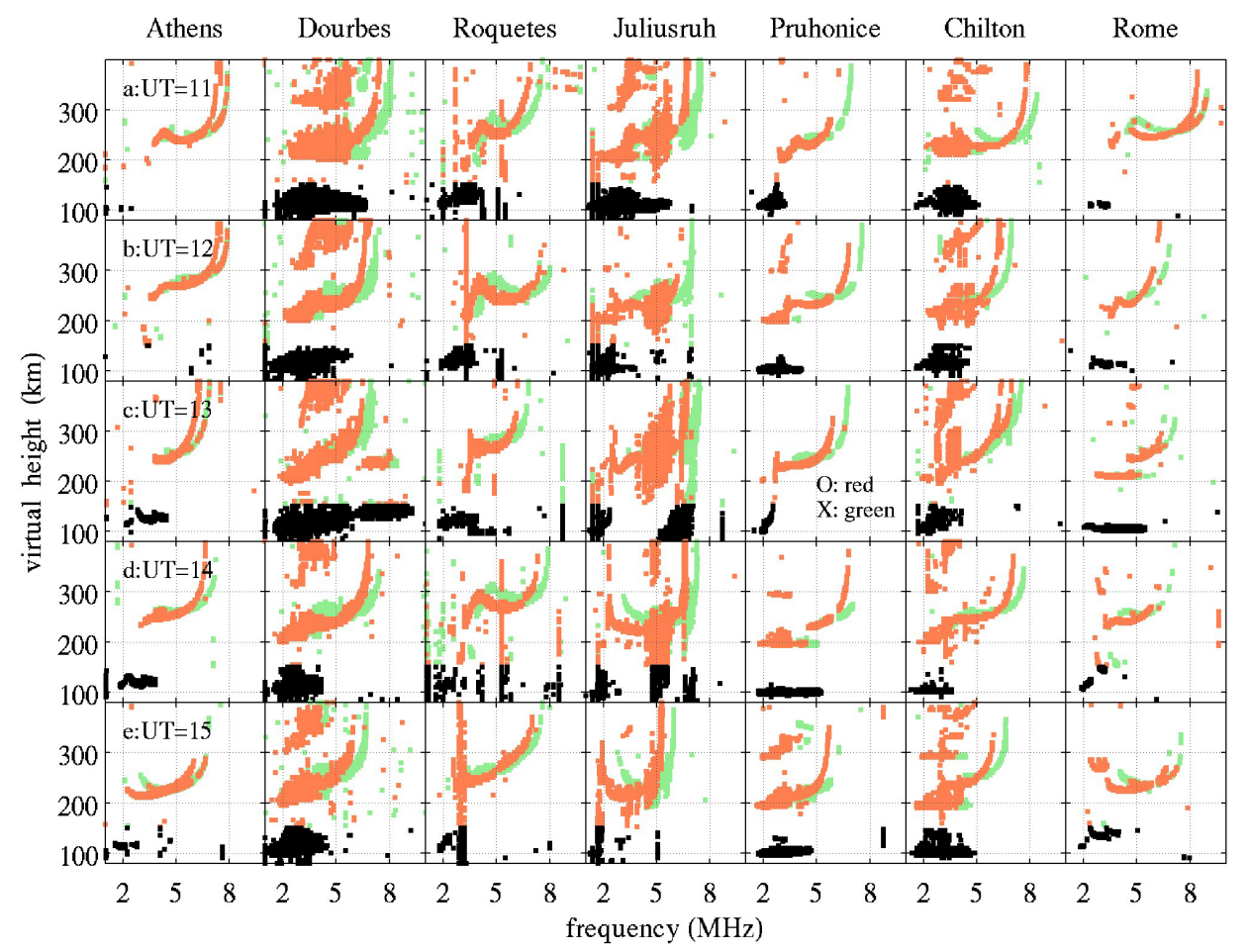

Figure 10. Raw ionogram: graph of the virtual height plotted against frequency. The panels from left to right are for the seven ionosondes, with the name given at the top. Panels a to e are for 11:00 to 15:00 UT at $1 \mathrm{~h}$ interval on day 294 of 2006. Ordinary and extraordinary returned waves are represented by the red and green dots, respectively. The wave traces below $\sim 150 \mathrm{~km}$ are given by the black dots to highlight the occurrence of sporadic E layer.

because of the high collision frequency between ionization and neutral particles over the lower altitude. (2) According to Whitehead (1989), the thickness of $E_{\mathrm{S}}$ is usually less than $4 \mathrm{~km}$. As indicated in Fig. 10, sometimes the vertical extent of echo trace can be larger than $10 \mathrm{~km}$. This might have additional drivers beyond $\mathrm{E}_{\mathrm{s}}$. The echo trace in ionograms could have a variety of sources (Maruyama et al., 2006). However, we are sure that these irregularities, which can cause echo traces in ionograms, will cause the RO SNR fluctuations too if the horizontal extent is sufficiently long.

We have not seen any cases of the broad $E_{S}$ occurrence that is reported in the previous literature. One reason is that the available $\mathrm{E}_{\mathrm{s}}$ observations from global ionosondes and CSR/ISRs still have far less coverage than necessary to study this phenomenon. Another reason is that the ionosondes mainly used have a lower frequency limitation, as we stated before. By contrast, the high-resolution RO radio wave signal is very sensitive to the layered structure in the ionosphere, which has been proved by the simulation studies by Yeh et al. (2012) and Zeng and Sokolovskiy (2010). During that selected case, the ionosphere is geomagnetically quiet (minimum Dst index is $-28 \mathrm{nT}$ ). We can exclude the potential effects from the storm time penetration electric field, which can result in broad region $\mathrm{E}_{\mathrm{S}}$ occurrence as reported by some studies (Abdu et al., 2014). The region of simulta- neous occurrence of $\mathrm{E}_{\mathrm{S}}$ has a width of roughly $50^{\circ}\left(10-60^{\circ}\right)$ in latitude and $65^{\circ}\left(-20-45^{\circ}\right)$ in longitude. We have actually found some other cases which show quasi-simultaneous $E_{S}$ occurrence in a much larger area, especially in the East Asia region. It has not been selected to be shown here because fewer colocated ionosondes are available to do the evaluation there. Our results strongly support the non-sporadic property of $E_{\mathrm{s}}$, as proposed by Haldoupis (2011) and Mathews (1998). However, current RO observations are still far less than sufficient to map the global $\mathrm{E}_{\mathrm{s}}$ at any time. In the near future, with the dramatic increase of available RO events from different planned RO missions especially COSMIC-2 (Yue et al., 2014), we will be able to map the global $\mathrm{E}_{\mathrm{s}}$ occurrence routinely. It will benefit $E_{\mathrm{S}}$ research as well as some applications, such as the long-distance communication at Very High Frequency (VHF) frequencies via reflections from $\mathrm{E}_{\mathrm{s}}$ layers.

\subsection{Wind shear theory}

Wind shear theory has been used to successfully explain the $\mathrm{E}_{\mathrm{S}}$ occurrence, especially in the middle latitude regions in the past century (Haldoupis, 2011; Whitehead, 1989). It has been generally accepted by the community and relatively well understood. In this study, we have only shown some cases of RO $E_{\mathrm{s}}$ observations. It is hard to examine the wind shear theory in detail. Multiple observations, statistical anal- 


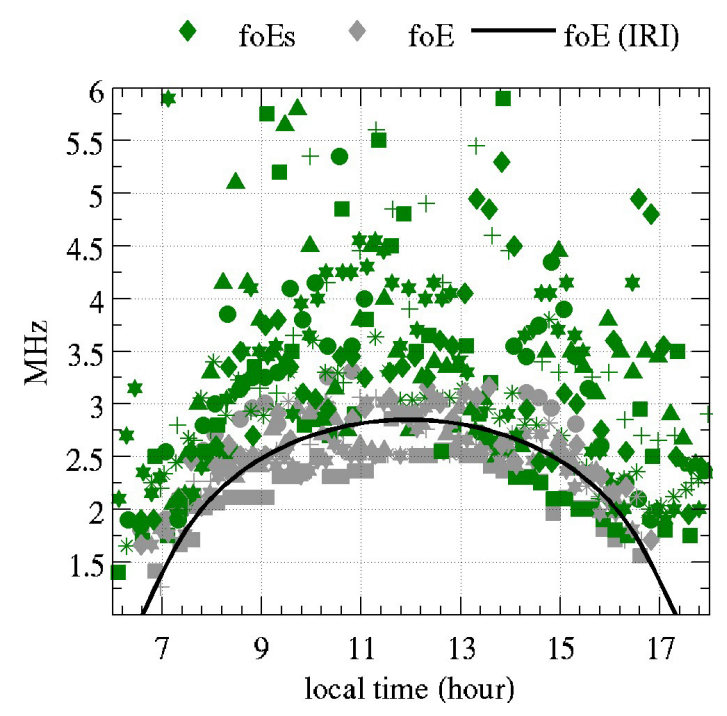

Figure 11. Local time variation of the sporadic E layer critical frequency (foEs, green) and the E layer critical frequency (foE, grey) observed by seven selected ionosondes and the corresponding IRI modeled foE results (black line) during 2006.294. The results of different ionosondes are distinguished by the dot shape. The IRI model results are corresponding to the mean latitude and longitude of seven ionosonde stations.

ysis, and theoretical simulation would be helpful in a further study to address this issue. Yeh et al. (2012) and Chu et al. (2014) have examined the wind shear theory based on RO $\mathrm{E}_{\mathrm{s}}$ occurrence in great detail. In Chu et al. (2014), they compared the COSMIC $\mathrm{E}_{\mathrm{S}}$ global morphology with the parameters that control the wind shear, including the global horizontal magnetic field intensity, global $\mathrm{Fe}^{+}$distribution from the Whole-Atmosphere Community Climate Model (WACCM) model calculation (Feng et al., 2013), and the meridional and zonal winds from the Horizontal Wind Model (HWM) model. Based on these parameters, they also calculated the global distribution of the divergence of the vertical $\mathrm{Fe}^{+}$flux. According to their results, the wind shear can explain the global distribution of $E_{S}$ and their altitude, local time, seasonal, and hemispheric asymmetry quite well, especially at middle latitudes. The tidal wind and geomagnetic field are quite stable. According to Feng et al. (2013), the $\mathrm{Fe}^{+}$density is also substantial and distributed globally. We can conclude that the simultaneous occurrence of $\mathrm{E}_{\mathrm{s}}$ in a broad region under wind shear theory is possible. Case 2 therefore supports the wind shear theory. It also demonstrates the advantages of RO signals in terms of high sensitivity to sporadic E occurrence.

\subsection{Potential improvement on the neutral radio occultation retrievals with a better understanding of $E_{s}$ occurrence}

In this study, we have demonstrated that the GNSS RO signals would be useful to investigate the complex $E_{S}$ occurrence in the ionosphere. However, on the other hand, the occurrence of $\mathrm{E}_{\mathrm{S}}$ will degrade the retrieved data quality in the lower atmosphere, including profiles of bending angle, refractivity, and temperature in the troposphere and stratosphere (Mannucci et al., 2011). Currently, in the RO neutral data retrievals, the most frequently used method to calibrate the ionospheric bending effect is the linear combination of the L1 and L2 bending angle interpolated to the same impact parameter (Schreiner et al., 2011). During the occurrence of $E_{s}$, the ionosphere will cause a much larger bending effect and a multipath effect on both L1 and L2, which will make the linear combination of L1 and L2 bending angles less accurate. In addition, the occurrence of $E_{S}$ itself will cause higher observational uncertainty in the GNSS signals. Small-scale ionospheric irregularity including the $\mathrm{E}_{\mathrm{s}}$ and $\mathrm{F}$ region has been one of the most significant error sources of neutral RO data retrievals, especially in the upper stratosphere (Schreiner et al., 2011). We have compared the global $\mathrm{E}_{\mathrm{S}}$ occurrence and the standard deviation of bending angles between 60 and $80 \mathrm{~km}$ derived from COSMIC RO data in detail. It is found that both the $\mathrm{E}_{\mathrm{S}}$ occurrence and bending angle standard deviation show a similar global distribution, seasonal variation, and local time variation, especially in the middle- and high-latitude regions. It implies that the occurrence of $\mathrm{E}_{\mathrm{S}}$ dominates the bending angle errors in middleand high-latitude regions. The standard deviation in bending is $\sim 10^{-6}$ radiance, which means it is not negligible in the upper stratosphere. In the equatorial region, the bending angle standard deviations show a maximum at sunset, which is caused by the equatorial $\mathrm{F}$ layer scintillation. Having a better understanding of $\mathrm{E}_{\mathrm{s}}$ will definitely be helpful in improving the neutral RO retrievals, especially in the upper stratosphere.

\section{Conclusions}

In this case study, the high-resolution GNSS RO signals from multiple missions processed in UCAR/CDAAC are used to investigate the complex $\mathrm{E}_{\mathrm{S}}$ layer structures. The selected cases are evaluated by colocated simultaneous RO events and independent observations from lidar and ionograms. We come to the following key conclusions:

1. The $\mathrm{E}_{\mathrm{s}}$ occurrence could be identified from the RO measurements by either the relative slant TEC peak or the SNR fluctuations (or sometimes the U shape).

2. Only the $E_{\mathrm{s}}$ from the defined $\mathrm{E}_{\mathrm{s}}$ occurrence area (EOA) can result in $\mathrm{E}_{\mathrm{S}}$-related features in an $\mathrm{RO}$ event. 
3. When assigning the observations to the tangent height, either SNR or TEC might show multiple $\mathrm{E}_{\mathrm{S}}$ layer structures. Based on the evaluations between colocated simultaneous RO events and between RO and lidar observations, we conclude that some of these do manifest the multiple $\mathrm{E}_{\mathrm{s}}$ layered structures.

4. We have found some cases that show the occurrence of $\mathrm{E}_{\mathrm{S}}$ in a broad region during a certain time interval. This result is validated by independent ionosonde observations.

5. These complex $\mathrm{E}_{\mathrm{S}}$ structures could be understood well using the popular wind shear theory. Further studies could benefit both $\mathrm{E}_{\mathrm{s}}$ mechanism research and relevant applications.

6. A better understanding of $E_{S}$ occurrence will be helpful for improving the RO-retrieved data quality in the upper stratosphere.

Acknowledgements. This material is based upon work supported by the National Science Foundation under Cooperative Agreement AGS-1033112. X. Xue acknowledges the support by the Project (KJCX2-EW-J01) of the Chinese Academy of Science. We acknowledge the usage of lidar data from the Chinese Meridian Project and ionosonde data accessed through the Lowell Global Ionospheric Radio Observatory (GIRO) Data Center (LGDC) Digital Ionogram DataBase (DIDB). We appreciate the organizations presented in Table 1 making their ionosondes observations publicly available.

Edited by: J. Y. Liu

\section{References}

Abdu, M. A., de Souza, J. R., Batista, I. S., Santos, A. M., Sobral, J. H. A., Rastogi, R. G., and Chandra, H.: The role of electric fields in sporadic E layer formation over low latitudes under quiet and magnetic storm conditions, J. Atmos. Solar-Terr. Phys., 115-116, 95-105, doi:10.1016/j.jastp.2013.12.003, 2014.

Anthes, R. A.: Exploring Earth's atmosphere with radio occultation: contributions to weather, climate and space weather, Atmos. Meas. Tech., 4, 1077-1103, doi:10.5194/amt-4-1077-2011, 2011.

Arras, C., Wickert, J., Beyerle, G., Heise, S., Schmidt, T., and Jacobi, C.: A global climatology of ionospheric irregularities derived from GPS radio occultation, Geophys. Res. Lett., 35, L14809, doi:10.1029/2008GL034158, 2008.

Arras, C., Jacobi, C., and Wickert, J.: Semidiurnal tidal signature in sporadic E occurrence rates derived from GPS radio occultation measurements at higher midlatitudes, Ann. Geophys., 27, 25552563, doi:10.5194/angeo-27-2555-2009, 2009.

Axford, W. I.: The formation and vertical movement of dense ionized layers in the ionosphere due to neutral wind shears, J. Geophys. Res., 68, 769-779, 1963.
Bernhardt, P. A.: The modulation of sporadic-E layers by KelvinHelmholtz billows in the neutral atmosphere, J. Atmos. SolarTerr. Phys., 64, 1487-1504, 2002.

Bilitza, D. and Reinisch, B. W.: International Reference Ionosphere 2007: Improvements and new parameters, Adv. Space Res., 42, 599-609, doi:10.1016/j.asr.2007.07.048, 2008.

Chu, Y. H. and Wang, C. Y.: Interferometry observations of threedimensional spatial structures of sporadic $E$ irregularities using the Chung-Li VHF radar, Radio Sci., 32, 817-832, 1997.

Chu, Y. H., Wang, C. Y., Wu, K. H., Chen, K. T., Tzeng, K. J., Su, C. L., Feng, W., and Plane, J. M. C.: Morphology of sporadic E layer retrieved from COSMIC GPS radio occultation measurements: Wind shear theory examination, J. Geophys. Res., 119, 2117 2136, doi:10.1002/2013JA019437, 2014.

Cosgrove, R. B. and Tsunoda, R. T.: Simulation of the nonlinear evolution of the sporadic-E layer instability in the nighttime midlatitude ionosphere, J. Geophys. Res., 108, 1283, doi:10.1029/2002JA009728, 2003.

Dou, X.-K., Xue, X. H., Li, T., Chen, T. D., Chen, C., and Qiu, S.C.: Possiblerelations between meteors, enhanced electron density layers, and sporadic sodiumlayers, J. Geophys. Res., 115, A06311, doi:10.1029/2009JA014575, 2010.

Dou, X. K., Qiu, S. C., Xue, X. H., Chen, T. D., and Ning, B. Q.: Sporadic and thermospheric enhanced sodium layers observed by a lidar chain over China, J. Geophys. Res., 118, 6627-6643, doi:10.1002/jgra.50579, 2013.

Feng, W., Marsh, D. R., Chipperfield, M. P., Janches, D., Hoffner, J., Yi, F., and Plane, J. M. C.: A global atmospheric model of meteoric iron, J. Geophys. Res. Atmos., 118, 9456-9474, doi:10.1002/jgrd.50708, 2013.

Foelsche, U., Scherllin-Pirscher, B., Ladstädter, F., Steiner, A. K., and Kirchengast, G.: Refractivity and temperature climate records from multiple radio occultation satellites consistent within $0.05 \%$, Atmos. Meas. Tech., 4, 2007-2018, doi:10.5194/amt-4-2007-2011, 2011

Fytterer, T., Arras, C., and Jacobi, C.: Terdiurnal signatures in sporadic E layers at midlatitudes, Adv. Radio Sci., 11, 333-339, doi:10.5194/ars-11-333-2013, 2013.

Galkin, I. A., Kitrosser, D. F., Kecic, Z., and Reinisch, B. W.: Internet access to ionosondes, J. Atmos. Solar-Terr. Phys., 61, 181186, 1999.

Gardner, C. S., Kane, T. J., Senft, D. C., Qian, J., and Papen, G C.: Simultaneous observations of sporadic E, $\mathrm{Na}, \mathrm{Fe}$, and $\mathrm{Ca}^{+}$ layers at Urbana, Illinois: Three case studies, J. Geophys. Res., 98, 16865-16873, doi:10.1029/93JD01477, 1993.

Haldoupis, C.: A Tutorial Review on Sporadic E Layers, Aeronomy of the Earth's Atmosphere and Ionosphere, IAGA Special Sopron Book Series 2, 381-394, 2011.

Hocke, K., Igarashi, K., Nakamura, M., Wilkinson, P., Wu, J., Pavelyev, A., and Wikert, J.: Global sounding of sporadic E layers by the GPS/MET radio occultation experiment, J. Atmos. SolarTerr. Phys., 63, 1973-1980, doi:10.1016/S1364-6826(01)000633, 2001

Hysell, D. L., Nossa, E., Larsen, M. F., Munro, J., Smith, S., Sulzer, M. P., and González, S. A.: Dynamic instability in the lower thermosphere inferred from irregular sporadic E layers, J. Geophys. Res., 117, A08305, doi:10.1029/2012JA017910, 2012.

Li, G., Ning, B., Patra, A. K., Abdu, M. A., Chen, J., Liu, L., and Hu, L.: On the linkage of daytime $150 \mathrm{~km}$ echoes and abnormal in- 
termediate layer traces over Sanya, J. Geophys. Res., 118, 72627267, doi:10.1002/2013JA019462, 2013.

Liu, J. Y., Lin, C. Y., Lin, C. H., Tsai, H. F., Solomon, S. C., Sun, Y. Y., Lee, I. T., Schreiner, W. S., and Kuo, Y. H.: Artificial plasma cave in the low-latitude ionosphere results from the radio occultation inversion of the FORMOSAT-3/COSMIC, J. Geophys. Res., 115, A07319, doi:10.1029/2009JA015079, 2010.

Mannucci, A. J., Ao, C. O., Pi, X., and Iijima, B. A.: The impact of large scale ionospheric structure on radio occultation retrievals, Atmos. Meas. Tech., 4, 2837-2850, doi:10.5194/amt-42837-2011, 2011.

Maruyama, T., Saito, S., Yamamoto, M., and Fukao, S.: Simultaneous observation of sporadic $\mathrm{E}$ with a rapid-run ionosonde and VHF coherent backscatter radar, Ann. Geophys., 24, 153-162, doi:10.5194/angeo-24-153-2006, 2006.

Mathews, J. D.: Sporadic E: Current views and recent progress, J. Atmos. Solar-Terr. Phys., 60, 413-435, doi:10.1016/S13646826(97)00043-6, 1998.

Mathews, J. D., Machuga, D. W., and Zhou, Q.: Evidence for electrodynamic linkages between spread-F, ion rain, the intermediate layer, and sporadic E: results from observations and simulations, J. Atmos. Solar-Terr. Phys., 63, 1529-1543, 2001.

Pavelyev, A. G., Liou, Y. A., Zhang, K., Wang, C. S., Wickert, J., Schmidt, T., Gubenko, V. N., Pavelyev, A. A., and Kuleshov, Y.: Identification and localization of layers in the ionosphere using the eikonal and amplitude of radio occultation signals, Atmos. Meas. Tech., 5, 1-16, doi:10.5194/amt-5-1-2012, 2012.

Reinisch, B. W. and Galkin, I. A.: Global ionospheric radio observatory (GIRO), Earth Planet Space, 63, 377-381, doi:10.5047/eps.2011.03.001, 2011.

Schreiner, W., Rocken, C., Sokolovskiy, S., Syndergaard, S., and Hunt, D.: Estimates of the precision of GPS radio occultations from the COSMIC/FORMOSAT-3 mission, Geophys. Res. Lett., 34, L04808, doi:10.1029/2006GL027557, 2007.

Schreiner, W., Sokolovskiy, S., Hunt, D., Rocken, C., and Kuo, Y.-H.: Analysis of GPS radio occultation data from the FORMOSAT-3/COSMIC and Metop/GRAS missions at CDAAC, Atmos. Meas. Tech., 4, 2255-2272, doi:10.5194/amt4-2255-2011, 2011.

Smith, L. G. and Miller, K. L.: Sporadic-E layers and unstable wind shears, J. Atmos. Terr. Phys., 42, 45-50, 1980.

Sokolovskiy, S., Schreiner, W., Rocken, C., and Hunt, D.: Detection of high-altitude ionospheric irregularities with GPS/MET, Geophys. Res. Lett., 29, 1033, doi:10.1029/2001GL013398, 2002.

Straus, P. R., Anderson, P. C., and Danaher, J. E.: GPS occultation sensor observations of ionospheric scintillation, Geophys. Res. Lett., 30, 1436, doi:10.1029/2002GL016503, 2003.
Wakabayashi, M. and Ono, T.: Multi-layer structure of mid-latitude sporadic-E observed during the SEEK-2 campaign, Ann. Geophys., 23, 2347-2355, doi:10.5194/angeo-23-2347-2005, 2005.

Wang, C.: New chains of space weather monitoring stations in China, Space Weather, 8, S08001, doi:10.1029/2010SW000603, 2011.

Whitehead, J. D.: Recent work on midlatitude and equatorial sporadic E, J. Atmos. Terr. Phys., 51, 401-424, doi:10.1016/00219169(89)90122-0, 1989.

Wickert, J., Pavelyev, A. G., Liou, Y. A., Schmidt, T., Reigber, C., Igarashi, K., Pavelyev, A. A., and Matyugov, S.: Amplitude variations in GPS signals as possible indicator of ionospheric structures, Geophys. Res. Lett., 31, L24801, doi:10.1029/2004GL020607, 2004.

Wu, D. L., Ao, C. O., Hajj, G. A., de la Torre Juarez, M., and Mannucci, A. J.: Sporadic E morphology from GPSCHAMP radio occultation, J. Geophys. Res., 110, A01306, doi:10.1029/2004JA010701, 2005.

Xue, X. H., Dou, X. K., Lei, J., Chen, J. S., Ding, Z. H., Li, T., Gao, Q., Tang, W. W., Cheng, X. W., and Wei, K.: Lower thermospheric enhanced sodium layers observed at low latitude and possible formation: Case studies, J. Geophys. Res., 118, 24092418, doi:10.1002/jgra.50200, 2013.

Yeh, W.-H., Huang, C.-Y., Hsiao, T.-Y., Chiu, T.-C., Lin, C.-H., and Liou, Y.-A.: Amplitude morphology of GPS radio occultation data for sporadic-E layers, J. Geophys. Res., 117, A11304, doi:10.1029/2012JA017875, 2012.

Yue, X., Wan, W., Liu, L., and Ning, B.: An empirical model of ionospheric foE over Wuhan, Earth Planets Space, 58, 323-330, 2006.

Yue, X., Schreiner, W. S., Kuo, Y.-H., Hunt, D. C., Wang, W., Solomon, S. C., Burns, A. G., Bilitza, D., Liu, J.-Y., Wan, W., and Wickert, J.: Global 3-D Ionospheric Electron Density Reanalysis based on Multi-Source Data Assimilation, J. Geophys. Res., 117, A09325, doi:10.1029/2012JA017968, 2012.

Yue, X., Schreiner, W. S., Pedatella, N., Anthes, R. A., Mannucci, A. J., Straus, P. R., and Liu, J.-Y.: Space Weather Observations by GNSS Radio Occultation: From FORMOSAT3/COSMIC to FORMOSAT-7/COSMIC-2, Space Weather, 12, 616-621, doi:10.1002/2014SW001133, 2014.

Zeng, Z. and Sokolovskiy, S.: Effect of sporadic E cloud on GPS radio occultation signal, Geophys. Res. Lett., 37, L18817, doi:10.1029/2010GL044561, 2010.

Zhang, K., Fu, E., Silcock, D., Wang, Y., and Kuleshov, Y.: An investigation of atmospheric temperature profiles in the Australian region using collocated GPS radio occultation and radiosonde data, Atmos. Meas. Tech., 4, 2087-2092, doi:10.5194/amt-42087-2011, 2011. 